\title{
12. RACISMO E ULTRANEOLIBERALISMO: Uma abordagem sobre a expropriação de direitos das populações negras na crise contemporânea do
} capital $^{*}$

Ana Paula Procopio da Silva

O capítulo aborda a relação entre racismo e ultraneoliberalismo para as reflexões acerca da expropriação de direitos na crise contemporânea do capital, como expressão da dinâmica estrutural que entrelaça capitalismo e relações raciais nas particularidades da formação sócio-histórica brasileira. As crises gerais e específicas são processos inerentes às contradições que organizam o capitalismo, ou seja, têm caráter estrutural, portanto, suas determinações remetem à estrutura social que organiza as relações sociais que as desencadeiam. Contudo, essas relações não são sustentadas unicamente pelo conflito entre capital e trabalho assalariado na sociedade capitalista. O racismo é um elemento estrutural e estruturante das relações de dominação e exploração de classe, que não se origina nestas relações, mas que toma uma forma especificamente capitalista. A funcionalidade do racismo moderno ao capitalismo o torna essencial para compreender não somente o sistema, mas as respostas racializadas à sua crise. A crise contemporânea do capital assume especificidades críticas em sua reverberação sobre grupos sociais historicamente submetidos a processos de discriminação sistemática, que se revertem em uma estratificação social constituída de iniquidades políticas e econômicas materializadas na forma de pobreza, de salários mais baixos, de menor acesso aos sistemas de saúde, educação e empregos formais, de maiores chances de encarceramento e de morte, como é o caso das populações negras no Brasil. Uma expressão contundente da relação entre ultraneoliberalismo e racismo no país é a Lei n. 13.429, de 31 de março de 2017 - que alterou a legislação so-

*DOI- 10.29388/978-65-86678-47-5-f.307-322 
bre o trabalho temporário e a terceirização - expropriando direitos trabalhistas e disponibilizando força de trabalho majoritariamente negra e pobre para a superexploração, para a acumulação do capital e para a morte.

\section{Crise do capital e racismo: aspectos estruturais}

As crises gerais e específicas são processos inerentes às contradições que organizam o capitalismo, ou seja, têm caráter estrutural, portanto, suas determinações remetem à estrutura das relações sociais que as desencadeiam, estão inscritas na própria lógica de acumulação do sistema. Nesta direção, o racismo um elemento estrutural e estruturante das relações de dominação e exploração de classe, que não se origina nestas relações, mas que toma uma forma especificamente capitalista é essencial para compreender não somente o sistema, mas as respostas racializadas às suas crises.

O processo de produção capitalista depende de uma expansão permanente da produção e de uma acumulação incessante de capital, contudo, em função das relações entre Estado e sociedade, das reivindicações das classes trabalhadoras, da organização de políticas sociais ambientais e sistemas de direitos humanos foram impostos limites históricos que se chocam com as contradições que organizam a sociabilidade capitalista, consubstanciada pelos direitos liberais.

As crises ocorrem quando o processo econômico capitalista não encontra compatibilidade com as instituições e as normas que deveriam manter a instabilidade, demonstrando então a incapacidade do sistema em determinados momentos da história de promover a integração por meio das regras sociais vigentes. O que significa que tanto não existe capitalismo sem crise como não existe manutenção de altas taxas de lucros sem incremento da exploração racial e sexual do trabalho.

Particularmente, desde os anos 1990, o mundo tem registrado uma diversidade de crises financeiras, que são expressões regionais da dinâmica contraditória do sistema. Todas as crises, não somente as financeiras compõem essa dinâmica. Contudo, as crises cíclicas que desde o século XIX movimentam o sistema não tem uma capaci- 
dade inerente de derrui-lo. Ao contrário, sem a ação coletiva, massiva e organizada para a sua destruição, as crises, pelas estratégias que o próprio capitalismo saca para o seu enfrentamento, redundam em mais capitalismo, sempre um pouco pior.

A crise sistêmica "que não é uma mera crise que se manifesta quando a acumulação capitalista se vê obstaculizada ou impedida" (NETTO, 2012), mas que envolve toda a estrutura do capital tem três demarcações históricas: 1873, 1929 e 2008.

A primeira grande crise do capitalismo, que emergiu em 1873, atingindo principalmente as potências do capitalismo europeu durou até 1896 e suas estratégias de enfrentamento foram assentadas no imperialismo eno neocolonialismo.

Achille Mbembe no livro Crítica da razão negra apresenta a relação intrínseca entre racismo, colonialismo e imperialismo: "[...] $\mathrm{Na}$ ordem colonial, a raça opera enquanto princípio do corpo político. A raça permite classificar os seres humanos em categorias físicas e mentais específicas. [...] A força passa a ser a lei, e a lei tem por conteúdo a própria força (2018a, p. 105). E conforme Almeida:

A bolsa de valores, o empreendimento colonial e o desenvolvimento do capital financeiro, são, ao fim e ao cabo, os fundamentos econômicos que permitiram a constituição do racismo e do nacionalismo como a manifestação da ideologia do capitalismo após a grande crise do século XIX (ALMEIDA, 2018, p. 159).

A divisão dos territórios e a partilha da África, concretizada na Conferência de Berlim ${ }^{1}$ (1884) dividiu formalmente o mundo entre os brancos civilizados europeus e os povos "bárbaros" e "selvagens". 0 neocolonialismo foi ordenado pelo racismo pseudocientífico como "requisito civilizatório". Esta visão de mundo fundamentou não só o roubo das riquezas naturais, mas a apropriação/negação de suas cul-

\footnotetext{
${ }^{1}$ A Conferência de Berlim realizada de 15 de novembro de 1884 a 26 de fevereiro de 1885 marcou a colaboração europeia na partição e divisão territorial da África com o objetivo de "regulamentar a liberdade do comércio nas bacias do Congo e do Níger, assim como novas ocupações de territórios sobre a costa ocidental da África". As fronteiras africanas foram divididas em 50 territórios ignorando os limites culturais e linguísticos já estabelecidos pelos africanos.
} 
turas, crenças, costumes, língua, religião, sistemas de parentesco e tudo o mais que os povos constituíram, estruturaram e dinamizaram durante séculos antes de terem seus territórios invadidos.

O discurso da inferioridade racial dos povos colonizados foi o argumento que instituiu a naturalização das atrocidades cometidas pelos ditos "civilizados" contra milhares de pessoas.

O racismo reforçado no neocolonialismo entrecruzou características biológicas e fenotípicas com características étnico-culturais e os próprios povos foram oprimidos a internalizar suas formas de existir como inferiores, atrasadas, subdesenvolvidas, cabendo aos povos desenvolvidos a "missão" de reeducá-los. Sob a alegação de que seriam portadoras de uma inerente desorganização política e propensão ao subdesenvolvimento as populações africanas foram expropriadas das suas terras, das riquezas naturais e da reivindicação de sua humanidade.

Com a passagem do colonialismo para o imperialismo e o neocolonialismo, o racismo foi remanejado em sua função instrumental. As metrópoles não somente propagaram, mas construíram a validação do discurso de que as ex-colônias seriam áreas habitadas por povos indolentes, geneticamente incapazes de constituir poupanças internas que os elevassem ao nível dos países brancos, que pelos seus próprios valores inatos teriam se desenvolvido, ao contrário do mundo não-branco fadado ao subdesenvolvimento (MOURA, 1994b).

Uma das ideias que legitimou a dominação com base nas incapacidades naturais foi a teoria do pensamento pré-lógico de Lévy Bruhl (1857-1939), que condenava alguns povos a uma posição de dependência circular. Isso porque defendia que o atraso era consequência de sua própria estrutura psicológica refratária e impermeável à experiência e à razão. A teoria estabeleceu uma divisão inflexível, pois esse pré-logismo impediria definitivamente determinados grupos humanos de passar de uma economia natural para a economia monetária (lógica).

O imperialismo promoveu a multiplicação das formas do racismo modernizando-o na medida da necessidade de estratégias mais sofisticadas de dominação. Assim, o pré-logismo derivou, por exemplo, na caracterização dos movimentos de libertação que se dinami- 
zavam nas regiões colonizadas ou dependentes como etnocêntricos, chauvinistas, xenófobos, nacionalistas e messiânicos, ou ainda como movimentos pré-políticos.

Embora o conceito de movimentos pré-políticos tenha sido cunhado por um historiador grandemente ligado ao pensamento marxista - E. J. Hobsbawn - acreditamos que ele seja eurocêntrico, elitista e uma forma neoliberal de analisar e interpretar a dinâmica social. Se o aceitarmos, seriam excluídos como políticos todos os movimentos do chamado Terceiro Mundo; a luta de Zapata e Pancho Villa, no México; a de Sandino, na Nicarágua; o movimento camponês de Pugachov, na Rússia; todos os movimentos de libertação da África, como o kinganbista, incluindo os Mau Mau e o de Lumumba. Tudo seria englobado sob o rótulo de milenarismo, salvacionismo ou messianismo, e seria descartada sua essência política. Os povos "inferiores" não tinham condições de entrar no sentido universal da história, eram a-históricos. Com isto justificava-se a repressão contra eles e os seus líderes. Fora dos padrões normativos dos valores políticos europeus, civilizados e "normais", não existiam movimentos que pudessem ser enquadrados como aceitos pelas nações dominadoras, como continuadores do "sentido" da civilização. As próprias lutas de libertação nacional eram (como acontece até hoje) consideradas revoltas intertribais, movimentos atípicos e perturbadores do processo civilizatório. Não tínhamos acesso à história, à civilização e à igualdade de direitos. A nossa inferioridade congênita e inapelável - biológica e psicológica - nos reduzia a satélites do processo civilizatório (MOURA, 1994b).

O racismo é componente estrutural do capitalismo. Não por acaso a sua fundamentação pseudocientífica se desenvolveu na Inglaterra e na França - berços das revoluções burguesas em suas dimensões política, ideológica e econômica - e depois se ampliou dinamicamente na Alemanha. Posteriormente, manteve-se, multiplicando e complexificando suas formas em estreita vinculação com o imperialismo dos países de capitalismo central em escala planetária e nas dinâmicas internas dos países de capitalismo dependente ou periférico. 
Os desdobramentos da grande depressão detonada na crise de 1929 e que culminam com a 2a Guerra Mundial tiveram como substrato a ascensão do nazifascismo que articulou o nacionalismo e a resolução da crise econômica à necessidade de uma reengenharia social que teve o genocídio de segmentos raciais específicos como objetivo.

No pós 2a Guerra, o arranjo social das grandes potências se organizou no sentido de uma acumulação baseada no fordismo e na proteção aos trabalhadores pela via do Estado de Bem Estar Social (Welfare State) o que instituiu a produção industrial em larga escala e o consumo de massa como indicadores de desenvolvimento econômico e social a serem replicados em todos os países, particularmente os chamados subdesenvolvidos. Assim, a receita para o subdesenvolvimento da América latina e do Caribe promoveu além da intensificação da industrialização, o endividamento externo, a superexploração ${ }^{2}$ e a assimetria do acesso a direitos aos segmentos historicamente alijados, com destaque para as mulheres negras.

Racismo e sexismo articulados mantiveram determinados segmentos nos setores menos protegidos e mais precarizados da economia, conformando a existência simultânea de processos desiguais e combinados de desenvolvimento, não como anomalia a ser consertada, mas como a forma necessária de manutenção do sistema em escala mundial.

Importante destacar que o pacto social do pós-guerra que criou a Declaração dos Direitos Humanos não incluiu o fim da violência colonial nos países africanos. Uma situação que apenas se reverteu com os movimentos africanos contra a dominação colonial nas décadas de 1960, 1970 e 1980. O que demonstra as contradições de uma sociedade que prega a igualdade e a universalidade de direitos ao mesmo tempo em que criminaliza os movimentos organizados por direitos de vida e de trabalho organizados por negros, mulheres, homossexuais, migrantes etc.

\footnotetext{
${ }^{2}$ [...] se define mais pela maior exploração da força física do trabalhador, encontra posição à exploração resultante do aumento de sua produtividade estende normalmente a expressarse no fato de que a força de trabalho se remunere por baixo de seu valor real. (MARINI, 2000, p. 160)
} 
O terceiro marco de crise sistêmica foi deflagrado em 2008 e começou a ser evidenciado nos anos 1970, nas transformações do capitalismo nos países centrais, pela crise do Estado de Bem Estar e do modo de produção fordista. Esta crise tem forjado profundas alterações no modelo de Estado e uma reestruturação produtiva que tem dado ao racismo novas complexidades. O sistema global do capital depois de vivenciar, nos países centrais, um ciclo de prosperidade adentrou uma nova fase, inédita, de crise estrutural, marcada pela continuidade de efeitos depressivos. Uma crise que se mostra longeva, sistêmica e estrutural e demarca a falência dos principais sistemas estatais de controle e regulação do capital no século XX exemplificados pela União das Repúblicas Socialistas Soviéticas - URSS e pelo Estado de Bem-Estar instituído em algumas sociedades capitalistas centrais (ANTUNES, 2009).

No período, a consolidação do neoliberalismo e a acumulação flexível determinaram tanto o fim da produção e do consumo de massa como o aumento da quantidade de "descartáveis" para o sistema. O desemprego nas suas formas conjuntural e estrutural que contribuiu para o enfraquecimento de sindicatos e movimentos sociais ocorreu concomitante ao ascenso de movimentos conservadores, racistas, xenófobos e fascistas que retomaram velhos discursos sobre quais os segmentos culpados pela crise, pela precarização e perda dos empregos. "Assim, a informalidade deixa de ser a exceção para tendencialmente tornar-se a regra, e a precarização passa a ser o centro da dinâmica do capitalismo flexível, se não houver contraposição forte a este movimento tendencial de escala global" (ANTUNES; DRUCK, 2015, p. 19).

A crise contemporânea é estrutural por ser uma crise na própria realização do valor - expressa nas crescentes quedas das taxas de lucro. O capital não tem como se desenvolver sem recorrer a taxa de utilização decrescente do valor de uso das mercadorias. As necessidades de amplos segmentos humanos são cada vez mais subordinadas à esfera da lucratividade, na medida em que é cada vez menos considerado o valor concreto das mercadorias para a manutenção de suas existências. As reformas, os ajustes econômicos e a redução das políticas sociais aprofundam essa subordinação. 
O objetivo de autorreprodução do capital encoberto sob os critérios de racionalidade, eficiência, eficácia e efetividade faz avançar também a corrosão da classe trabalhadora em escala global, a erosão do trabalho regulado e a ampliação das suas formas desprotegidas: empreendedorismo, cooperativismo e voluntariado que oscilam entre a superexploração e a autoexploração. É uma precarização estrutural da força de trabalho, mas que penaliza mais fortemente os segmentos negros femininos.

O enfrentamento capitalista da crise tem como estratégia a socialização das perdas do capital sobre a classe trabalhadora como um todo, seja pela via de redução dos salários diretos e/ou pelo contingenciamento dos salários indiretos, atingido mais largamente as populações negras, que são a maioria nas demandas por políticas públicas para sobreviver.

A racionalidade ditada pelo neoliberalismo impõe uma organização dos recursos públicos que reduz significativamente o financiamento das políticas públicas retirando das populações pobres, que são majoritariamente negras, quaisquer alternativas, que não sejam render-se a subalternização e a superexploração.

\section{Necropolítica e ultraneoliberalismo - crise do capital e ra- cismo}

Em todos os processos de colonização, genocídios, expropriação, tráfico de pessoas, escravidão e imperialismo ao longo dos séculos e até os dias atuais o corpo é o local por excelência onde as relações de poder se materializam como explorações e opressões para fins econômicos e políticos.

Achille Mbembe (2018b) racializa essa percepção através de suas indagações sobre quais as condições práticas em que o poder de matar, deixar viver ou expor à morte é exercido a partir das determinações de soberania relacionando a noção de biopoder aos conceitos de estado de exceção e estado de sítio. Isso porque a violência da escravidão moderna enquanto estrutura político-jurídica fundamenta e institucionaliza de forma irreversível, pelo menos nos termos da humanidade liberal, a expulsão dos negros. A necropolítica configura 
um sistema contemporâneo de hierarquização populacional escalonada em que determinadas vidas têm politicamente menos valor do que outras. Na atualidade, a soberania e o poder para decidir que vive e quem morre está assentada nos processos de desumanização dos negros constituídos na modernidade e tem como desdobramento a naturalização que banaliza e legitima mortes negras de forma direta ou não.

A crise contemporânea do capital assume especificidades críticas em sua reverberação sobre grupos sociais historicamente submetidos a processos de discriminação sistemática, que se revertem em uma estratificação social constituída de iniquidades políticas e econômicas materializadas na forma de pobreza, de salários mais baixos, de menor acesso aos sistemas de saúde, educação e empregos formais, de maiores chances de encarceramento e de morte, como é o caso das populações negras no Brasil.

A lógica neoliberal que faz da concorrência o princípio organizativo da vida social dinamiza os processos discriminatórios, ao mesmo tempo em que tem sua própria dinamização vinculada a manutenção de opressões e explorações em função das hierarquizações de classe, raça, gênero, orientação sexual e outros marcadores da existência humana, o que requer a participação ativa do Estado.

[...] ainda que admitam a necessidade de uma intervenção do Estado e rejeitem a pura passividade governamental, os neoliberais opõem-se a qualquer ação que entrave jogo da concorrência entre interesses privados. A intervenção do Estado tem até um sentido contrário: trata-se de não de limitar o mercado por uma ação de correção ou compensação do Estado, mas de desenvolver e purificar o mercado concorrencial por um enquadramento jurídico cuidadosamente ajustado. Não se trata mais de postular um acordo espontâneo entre os interesses individuais, mas de produzir as condições ótimas para que o jogo da rivalidade satisfaça o interesse coletivo (DARDOT; LAVAL, 2016, p. 69).

O que chamamos então de ultraneoliberalismo no Brasil são as exigências que ultrapassam as privatizações e os cortes dos recur- 
sos das políticas públicas, mesmo aquelas focalizadas e compensatórias. Estão sendo minados não somente todos os graus de resistência aos novos padrões de acumulação, mas verificamos o aumento expressivo da descartabilidade de populações negras e indígenas.

\section{O mercado de trabalho brasileiro e a Lei n. 13.429/2017: intensificação da necropolítica}

No pós-abolição, a massiva imigração europeia subvencionada em parte pelo Estado ${ }^{3}$ formou uma população livre superposta a população negra, como agente do sistema produtivo numa sociedade erigida sobre o escravismo, como a subalternização e a superexploração. A divisão racial do trabalho compulsória no escravismo, no contexto competitivo foi acionada como divisão social do trabalho encobrindo o fato de serem reservados aos negros os trabalhos mais precários, insalubres, desprestigiados e menos remunerados. A lógica de organização do trabalho esvaziada da componente racial assume uma aparência democrática, como se todos os trabalhadores a partir de 13 de maio de 1888 tivessem se tornado iguais em sua liberdade de venda da força de trabalho.

A partir da conjugação de interesses internos (bloco de poder escravista) e externos (imperialismo inglês) foi construída a política institucional para a passagem do escravismo ao trabalho livre no Brasil, uma transição sem perspectiva de mudanças sociais que alterassem significativamente a estratificação social.

O racismo mobilizado como ideologia de branqueamento do trabalho consolidou um imaginário negativo sobre os trabalhadores negros como incapazes de enfrentar os desafios do novo tipo de organização do trabalho, como trabalho assalariado. Isso porque,

[...] o trabalho escravo foi substituído pelo trabalho livre. Mas as estratégias de dominação antecipadamente estabelecidas fizeram com que o antigo escravo não entrasse sequer como

\footnotetext{
${ }^{3}$ Segundo Andrews (1998) 2,5 milhões de europeus migraram para o Brasil entre 1890 e 1914, sendo 987 mil com passagens de navio pagas por subsídios do Estado.
} 
força secundária desse processo, ficando como borra sem função expressiva.

O Brasil arcaico preservou os seus instrumentos de dominação, prestígio e exploração e o moderno foi absorvido pelas forças dinâmicas do imperialismo que também antecederam à Abolição na sua estratégia de dominação (MOURA, 1994a, p.103).

O mercado de trabalho brasileiros se constituiu caracterizado tanto pela heterogeneidade de vínculos como pela desproteção da grande massa de trabalhadores considerando a escolha por uma regulação estatal centrada numa base de proteção que priorizou o trabalhador formal. De modo concomitante, o Estado sempre possibilitou uma grande margem para que as condições de contratação da mão de obra se adaptassem aos interesses das empresas.

Nas primeiras décadas da CLT, ficaram de fora da regulação estatal os trabalhadores rurais e empregados domésticos, imprimindo ao mercado de trabalho brasileiro características como alta informalidade, expressiva participação do trabalho por conta própria, elevada rotatividade e baixa cobertura previdenciária (PELATIERI, 2013, p.34).

Em 2018, a Pesquisa Nacional por Amostra de Domicílios Contínua - PNAD Contínua, realizada pelo IBGE, mostrou que os grupos de populações brancas e negras respondiam por cerca de $99 \%$ da população brasileira: os brancos eram 43,1\%; os pretos, 9,3\%; e os pardos, 46,5\%. E como no total da população brasileira, as populações negras constituem também a maior parte da força de trabalho, compondo no ano em tela um contingente de 57,7 milhões de pessoas. No entanto, em relação à população desocupada e à população subutilizada (desocupados, os subocupados e a força de trabalho potencial), os negros são substancialmente mais representados - formando cerca de $2 / 3$ dos desocupados(64,2\%) e d os subutilizados $(66,1 \%)$.

No Brasil, o quadro trabalhista é historicamente marcado pela alta taxa de informalidade, ficando pouco acima dos $40 \%$ do total de empregados. No entanto, o racismo estrutural mantém a desigualdade entre negros e brancos. Em 2018, enquanto 34,6\% dos trabalha- 
dores brancos estavam em ocupações informais, entre os de cor ou raça preta ou parda esse percentual atingiu $47,3 \%$. No 3 o trimestre de 2019 eram mais de 38 milhões de pessoas trabalhando sem registro, sendo $65,2 \%$ dos desocupados pretos ou pardos. Os brancos representavam 34,0\%dessa distribuição(IBGE, 2019).

Uma expressão contundente da relação entre ultraneoliberalismo e racismo no país é a Lei no 13.429, de 31 de março de 2017 que alterou a legislação sobre o trabalho temporário e a terceirização - ampliação a margem de expropriação dos direitos trabalhistas e disponibilizando força de trabalho majoritariamente negra e pobre para a superexploração, para a acumulação do capital e para a morte.

As mudanças significativas no conteúdo da Lei no 6.019/1974, que antes regulava apenas o trabalho temporário têm sido invocadas como um marco disruptivo aos óbices do trabalho intermediado nas atividades-fim e nas atividades-meio dos empregadores. Por outro lado, a legislação foi aplicada em uma sociedade na qual os trabalhadores terceirizados recebem os menores salários, permanecem menos tempo nos empregos, acumulam as maiores jornadas, têm os maiores índices de acidentalidade e de adoecimentos em função do trabalho. Também são esses trabalhadores os mais desprotegidos no encerramento dos contratos, especialmente nos setores de vigilância e asseio e conservação em que a falta de pagamento e o não recebimento das verbas rescisórias são constantes.

A terceirização não somente intensifica a precarização da força de trabalho, mas acentua as iniquidades estruturalmente construídas por gênero e raça. A desresponsabilização do Estado brasileiro com os direitos sociais de trabalhadores negros não é novidade. Contudo, a situação atual caminha no sentido de inviabilizar as vidas das populações negras, particularmente as mulheres.

[...] nas bases da pirâmide social brasileira localizam-se as muIheres negras e pobres, pois são elas que executam os trabaIhos mais precários, subalternos, invisíveis e com a pior remuneração, como são os trabalhos terceirizados. Ou seja, podemos afirmar que há diferenciação em relação aos rebatimentos da terceirização em se tratando das mulheres, principalmente mulheres negras, uma vez que a formação social brasileira está 
assentada na desigualdade e nas opressões de classe, gênero e raça/etnia (PASSOS; NOGUEIRA, 2018, p.491).

A terceirização está alocada, majoritariamente, no setor de serviços ou na informalidade, campos de trabalho em que estão inseridas as populações negras. A Pesquisa de Emprego e Desemprego (PED) de 2018 mostrou que 73,7\% das mulheres negras que trabaIham na região metropolitana de São Paulo estão no setor de serviços. Também o trabalho doméstico e de cuidados, lócus de terceirização são compostos expressivamente por mulheres negras. Em 2014, $72 \%$ das 258 cuidadoras do setor de serviços residenciais terapêuticos do município do Rio de Janeiro eram negras e $26 \%$ brancas. No Brasil são 6 milhões de trabalhadores domésticos, sendo 5,7 milhões de mulheres e 3,9 milhões de mulheres negras, o que o trabalho doméstico representa cerca de $18,6 \%$ das ocupações das mulheres negras do país, o que de acordo como economista Marcelo Paixão: “É um percentual interessante, porque é mais ou menos o mesmo percentual coletado no Censo de 1872, antes da Lei Áurea: $25 \%$ das escravas trabalhavam como domésticas". Um comentário que sintetiza tanto os processos históricos que constituem a formação social brasileira como a barbárie contemporânea que articula racismo e ultraneoliberalismo no interior da crise contemporânea do capital.

\section{Referências}

ANDREWS, George Reid. Negros e brancos em São Paulo (18881988). São Paulo, EDUSC, 1998.

ANTUNES, Ricardo. A substância da crise. In: MÉSZÁROS, I. A crise estrutural do capital. São Paulo, Boitempo, 2009.

. ; DRUCK, Graça. A terceirização sem limites: a precarização

do trabalho como regra. O Social em Questão, Rio de Janeiro, ano 18, n. 34, p. 19-40, jul./dez. 2015.

ALMEIDA, Silvio Luiz de. 0 que é racismo estrutural? Belo Horizonte, Letramento, 2018. 
BRASIL. Lei n.o 13.429/2017. Altera dispositivos da Lei n o 6.019, de 3 de janeiro de 1974, que dispõe sobre o trabalho temporário nas empresas urbanas e dá outras providências; e dispõe sobre as relações de trabalho na empresa de prestação de serviços a terceiros. Disponível em: <http://www.planalto.gov.br/ccivil_03/_ato20152018/2017/lei/L13429.htm>. Acesso em 26 set. 2020.

DARDOT, Pierre; LAVAL, Christian. A nova razão do mundo: ensaio sobre a sociedade neoliberal. São Paulo, Boitempo, 2016.

DIEESE. Pesquisa de Emprego e Desemprego, Inserção da População Negra nos Mercados de Trabalho Metropolitanos. 2018. Disponível em: <https://www.dieese.org.br/analiseped/negros.html>. Acesso em 23 set. 2020.

IBGE. Desigualdades Sociais por Cor ou Raça no Brasil. Brasília, 2019. Disponível em: <https://biblioteca.ibge.gov.br/visualizacao/livros/ liv101681_informativo.pdf>. Acesso em 25 de set. 2020.

. Pesquisa Nacional por Amostrade Domicílios Contínua -

PNAD Contínua. Mercado de Trabalho Brasileiro, 3으 trimestre de 2019. Brasília, 2019. Disponível em: <https://www.ibge.gov.br/estatisticas/multidominio/condicoes-de-vida-desigualdade-e-pobreza/ 9173-pesquisa-nacional-por-amostra-de-domicilios-continua-trimestral.html?edicao=26039\&t=destaques $>$. Acesso em 25 de set. 2020. MARINI, Ruy Mauro. Dialética da Dependência. Petrópolis, Vozes; BuenosAires, Clacso, 2000.

MBEMBE, Achille . Crítica da razão negra. São Paulo, n-1, 2018a. . Necropolítica. São Paulo, n-1, 2018 b.

MOURA, Clovis. Dialética radical do Brasil negro. São Paulo, Anita, 1994a.

O racismo como arma ideológica de dominação, 1994b. Disponível em: <https://www.geledes.org.br/o-racismo-como-arma-ideologica-de-dominacao/>. Acesso em 14 de mar. 2020.

NETTO, Jose Paulo. Crise do capital e consequências societárias. Serv. Soc. Soc., São Paulo, n. 111, p. 413-429, jul./set. 2012. 
PAIXÃO, Marcelo. Brancos tem renda $85,3 \%$ maior que a dos brancos. Publicado em 22/11/2014. Disponível em: <https://odia.ig.com.br/ noticia/riosemfronteiras/2014-11-23/brancos-tem-renda-853-maiorque-a-dos-negros.html>. Acesso em 22 de set. 2020.

PASSOS, Rachel Gouveia; NOGUEIRA, Claudia Mazzei. O fenômeno da terceirização e a divisão sociossexuale racial do trabalho. R. Katál., Florianópolis, v. 21, n. 3, p. 484-503, set./dez. 2018.

PELATIERI, Patrícia et al. As desigualdades entre trabalhadores terceirizados e diretamente contratados: análise a partir dos resultados de negociações coletivas de categorias selecionadas. In: SANTANA, Pedro Marques de. Dependência e superexploração do trabalho no capitalismo contemporâneo. Brasília, Ipea; ABET, 2013.

\section{Sobre a autora}

Ana Paula Procópio - Assistente social e psicóloga, professora adjunta da Faculdade de Serviço Social da Universidade do Estado do Rio de Janeiro. Doutora em Serviço Social. Coordenadora do Programa de Estudos e Debates dos Povos Africanos e Afro-americanos - PROAFRO UERJ. Coordenadora da Residência Integrada e Multiprofissional em Saúde Mental da UERJ.

E-mail: anapaulaprocopio@yahoo.com.br 